\title{
Funding opportunities for clinical investigators in the early stages of career development in cardiovascular research
}

\author{
Robert J. Mentz and Richard C. Becker \\ Duke Clinical Research Institute, Duke University Medical Center, Duke University School of \\ Medicine, 2400 Pratt Street, Durham, NC 27705, USA
}

Robert J. Mentz: robert.mentz@duke.edu

\begin{abstract}
Contemporary cardiovascular research offers junior investigators the opportunity to explore the gamut of biomedical questions. Despite the recent reduction in the availability of funding mechanisms that have historically served as the primary pathways for investigators in the early stages of career development, there remain numerous traditional and non-traditional funding opportunities. This article highlights these opportunities in order to assist early career investigators in the development of a personalized research trajectory, which optimizes the potential for career success.
\end{abstract}

\section{Keywords}

Cardiovascular investigator; Grant opportunities; Funding; Junior researcher

\section{Background}

Contemporary cardiovascular research offers junior investigators the opportunity to explore the gamut of biomedical questions. Despite the recent reduction in the availability of funding mechanisms that have historically served as the primary pathways for investigators in the early stages of career development [1], there remain numerous traditional and nontraditional funding opportunities. This article highlights these opportunities in order to assist early career investigators in the development of a personalized research trajectory, which optimizes the potential for career success. We review relevant grants from the National Institutes of Health $(\mathrm{NIH})$, medical societies including those in general cardiology and cardiovascular subspecialties, the Veterans Affairs, industry-affiliated and institutionspecific opportunities (Table 1). We propose a strategy to identify relevant grants given an individual's level of training, previous experience, institutional opportunities and career goals (Fig. 1). We also highlight general characteristics of applications for these grants, which may increase the likelihood of successfully acquiring funding.

\section{National Institutes of Health grants}

The NIH offers extramural research grants that may be appropriate for junior investigators including the fellowship programs (F grants), institutional training grants ( $\mathrm{T}$ grants), career

(C) Springer Science+Business Media New York 2013

Correspondence to: Robert J. Mentz, robert . mentz z duke. edu.

Disclosures R.J. Mentz. has received research grants from Gilead Sciences, Inc and reimbursement for travel to scientific sessions/ clinical training from Medtronic, Thoratec and HeartWare. R.C. Becker has received research funding from AstraZeneca and Johnson and Johnson. He has served on scientific advisory boards for Portola, Daiichi-Sankyo, Boehringer-Ingelheim and Bayer. 
development awards (CDAs) (K grants) and the pathway to independence award (K99/R00) (Table 2) [2].

The NIH's Ruth L. Kirschstein National Research Service Award (NRSA) provides support for the early stages of postdoctoral training in biomedical research through the F32 grants. The F32 award goes to promising postdoctoral fellows, who demonstrate the potential to become independent investigators. It is suitable for trainees with little or no research experience. It supports a mentor-supervised emersion designed to position the trainee on the pathway for other CDAs. Individuals may receive up to 3 years of aggregate KirschsteinNRSA support at the postdoctoral level, including a combination of support from institutional training grants and individual fellowship awards. For further details visit: http:// grants.nih.gov/training/F_files_nrsa.htm.

Senior fellows may apply for the F33 award, which offers an opportunity to extend previous research in health-related areas as independent researchers. These awards enable individuals with at least 7 years of research experience beyond the doctorate who have progressed to the stage of independent investigator, to take time from regular professional responsibilities for the purpose of receiving training to increase their scientific capabilities. In most cases, this award is used to support sabbatical experiences for established independent scientists seeking support for retraining or additional career development.

Institutional training grants (T32) target individuals who are committed to a career in research and who plan to remain on the training grant or in a non-NRSA research experience for a minimum of 2 years. These are awarded to institutions that train fellows and residents, and are used to promote the education of future researchers. T grants are the major NIH funds that have traditionally been available to fellows and residents. Postdoctoral trainees must have received, as of the beginning date of the NRSA appointment, a doctoral degree from an accredited domestic or foreign institution. All trainees are required to pursue their research full time, normally defined as $40 \mathrm{~h}$ per week, or as specified by the sponsoring institution in accordance with its own policies. Appointments are normally made in 12month increments. Trainees should receive training in the skills necessary to apply for subsequent support through an individual fellowship, mentored CDA (K) program, or independent research project grant. For further details visit: http://grants.nih.gov/training/ T_Table.htm.

Although fellows can theoretically compete for career development (K) awards, these are designed to support individuals who have completed their training and are ready for faculty positions. Two of the most popular $\mathrm{K}$ awards are the mentored patient-oriented research CDA (K23) and the mentored clinical scientist development award (K08). The K08 and the $\mathrm{K} 23$ are identical in most respects, except for the scientific emphasis. The K23 award is intended to provide research-oriented clinicians the means to develop independent research skills and gain experience in experimental methods and approaches that will allow them to conduct patient-oriented research. Patient-oriented research is defined as research conducted with human subjects in which an investigator directly interacts with human subjects including investigating mechanisms of human disease, therapeutic interventions, clinical trials, and the development of new technologies. The mentored clinical scientist development award (K08) provides research development opportunities for clinicianscientists with varying degrees of research experience who are committed to developing into independent investigators skilled in the advanced methods and experimental approaches needed for laboratory and cardiovascular epidemiological and health services research. For further details visit: http://grants.nih.gov/training/careerdevelopmentawards.htm. 
The pathway to independence award (K99/R00) supports 1-2 years (K99 phase) of mentorsupervised postdoctoral training, followed by 3 years (R00 phase) of independent research within the context of the first junior faculty position. The program features a relatively new opportunity for promising postdoctoral scientists to receive both mentored and independent research support from the same award. The initiation of the R00 phase requires the applicant to obtain an independent position as a tenure-track assistant professor (or equivalent) and demonstrate the awardee's independence from the K99 mentor. This award involves a commitment of a minimum of $75 \%$ of total professional effort to the career development plan and the research program.

\section{Cardiovascular Society Grants: The American College of Cardiology (ACC) and American Heart Association (AHA)}

The ACCF/Merck Research Fellowship in cardiovascular disease and cardiometabolic disorders is a 1-year $\$ 70,000$ award for salary support for cardiology research for those currently in adult cardiology fellowship. Preference is given to individuals who have had no more than 2 years of prior full-time research experience. Recipients will be expected to pursue a full-time project in clinical research during their year of supported training. This protected year of research should occur either within or following their 3 years of required cardiology training. Proposals addressing cardiovascular disease and cardiometabolic disorders are encouraged including those that address pathophysiology, molecular genetics, metabolic abnormalities leading to cardiovascular disease, hypertension, heart failure, hyperlipidemia, inflammatory mechanisms and new pathways for drug discovery. Outcomes studies should focus on clinical/and or systems of care interventions, and use outcomes measures of importance to both patients and society. Proposals are encouraged that focus on gender, race, geographic, and economic inequalities in cardiovascular care.

The AHA Fellow-to-Faculty Transition Award provides funding for physician-scientist trainees in cardiovascular or stroke research from the completion of research training through the early years of the first faculty/staff position. This program provides 5 years of funding at $\$ 65,000$ annually for physician-scientist trainees in a supportive mentored experience during this period of transition. Postdoctoral Fellowship is designed to help a trainee initiate a career in cardiovascular research while obtaining significant research results. Research topics broadly relate to cardiovascular function and disease and stroke, or to related clinical, basic science, bioengineering or biotechnology, and public health problems, including multidisciplinary efforts. The program encourages early career investigators who have supportive mentoring relationships to engage in high-quality introductory and pilot clinical studies that will guide future strategies for reducing cardiovascular disease and stroke while fostering new research in clinical and translational science and encouraging community- and population-based activities.

\section{Other society and subspecialty funding}

The American Society of Hematology (ASH) Research Training Awards for Fellows include a Junior Investigator award for second and third-year fellows and Senior Investigator award for fourth and fifth-year fellows. The $\$ 50,000$ awards are designed to allow fellows in training the benefit of protected time for research for 1 year. They are designed to encourage junior researchers in hematology, or other hematology-related training programs to pursue a career in academic hematology.

The Heart Rhythm Society awards 1-year Research Fellowships to individuals interested in clinical and basic research relating to the latest advances in electrophysiology. These postdoctoral research fellowships include a 1-year stipend of $\$ 50,000$. Awardees must have a 
doctorate by the year of award activation and may not have completed three cumulative years of post-medical school or graduate school research. Proposed research must be relevant to the goals and aims of the society including epidemiological, community, clinical, and basic investigations within cardiac electrophysiology. Applicants should be intent on pursuing a career in independent research. Applicants must devote at least $80 \%$ of their effort to research or activities directly related to the proposed research.

The Heart Failure Society of America (HFSA) Research Fellowship is a full-year fellowship designed for individuals seeking specialty education and research training in the area of heart failure. The amount to be awarded will be based on the submitted budget, up to a maximum of $\$ 55,000$. Preference will be given to those whose research is a bridge or can be translated into the clinical care of patients with heart failure. At the time of award initiation, the awardee should have no more than seven post-doctoral years. Individuals with faculty appointments (above Instructor level) are not eligible for this fellowship award. The recipient must devote no $<80 \%$ of his/her time to research activities in heart failure.

The International Society for Cardiovascular Translational Research (ISCTR)-ACCF offers a Cardiovascular Translational Research Scholarship, which is a 1-year program with $\$ 60,000$ of salary support and is intended for a physician interested in translating basic biological and device concepts through pre-clinical and regulatory pathways and into clinical application. One year of previous interventional cardiology training is required. This program takes place onsite at Dignity Health, St. John's Hospital and will likely require relocation (California).

\section{Veterans Affairs}

The Veterans Health Administration Career Development program is intended for researchers investigating strategies to improve the health and care of our nation's veterans. The program provides opportunities for clinician and non-clinician biomedical and clinical researchers in all areas of the VAs research enterprise: biomedical laboratory, clinical science, health services, and rehabilitation research.

Candidates must be nominated by a VA Medical Center, but do not need to have a VA appointment until the start date of funding. There are two CDA levels which may be applicable to early career investigators. The CDA-1 is an entry-level career development program for clinicians no more than 2 years beyond clinical training; the suggested academic rank is Instructor. It provides 2 years of salary support. At the conclusion of the CDA-1 award, awardees may compete for advancement to a CDA-2. The CDA-2 is a midlevel program for research with some prior research experience but with academic rank not above Assistant Professor. It involves a career development plan and research project over a 3-5 year duration.

\section{Industry-funded grants}

Pharmaceutical and device companies sometimes offer investigator-initiated grant opportunities relevant to their products. These grants are frequently submitted through an online application. Grant amount may vary depending on programmatic needs. Many of these corporate grants undergo a review process similar to other grant mechanisms with involvement of an internal review committee. Potential pros of these grants may include flexible submission schedules, expedited review, and the ability to establish a longitudinal relationship with a company to investigate a particular area of interest. Cons of these funding mechanisms include issues related to conflict of interest and the need to align projects with a company's mission and therapeutic focus. It may be possible for institutions to further align with companies in order to establish a structured internal research program 
with predetermined funding allotments and a review panel including those from the company and institution.

\section{Institution-based grants}

Institutional grants range from those providing seed money for pilot and preliminary work to full academic funding. Strategies to identify these grants will be institution specific, but commonly involve searching the institution's website, reviewing message boards and reviewing opportunities with mentors and colleagues. Examples of funding mechanisms include grants from academic medical centers as well as institute-level funding such as those from Cardiovascular Research Centers within the larger medical entity.

\section{Characteristics of a strong grant application}

While there are specific criteria that are unique to each grant opportunity, there are several features that are central to most strong grant applications [3]. These include the commitment of the applicant, quality of the project, and the specific training environment with an emphasis on the dedication and experience of the mentor. The applicant should clearly lay out his/her proposed project and career plan as supported by the trainee's academic record and prior research experience and/or publications (if possible). There should be a clear rationale supporting the need for the proposed grant funding with documentation of the trainee's ability to complete the work as discussed in letters of reference.

The proposal should address an important problem of significance to the funding agency. $\mathrm{He} /$ she should outline how the work will affect the concepts, methods and technologies that drive the area of research. The inclusion and assessment of preliminary data, whether generated by the applicant or others, should be put into perspective so that the new project is relevant. The conceptual design, methods and analyses should be adequately developed, feasible and appropriate to the aims of the project. If appropriate, the applicant should acknowledge potential problem areas and consider alternative tactics.

The quality of the training environment and mentor should support project success. Both the mentor and the trainee's institution should demonstrate commitment to the project. The mentor should be an independent investigator with appropriate experience to direct the proposed research training, as evidenced by his/her track record regarding productivity, funding and prior trainees. A specific mentoring plan needs to be detailed that makes explicit the mentor's ability to guide the awardee's completion of research training and compatibility of the mentor's research area with that of the applicant to support direct acquisition of the appropriate scientific skills and academic output.

\section{Conclusions}

There are numerous traditional and non-traditional funding opportunities for junior investigators in cardiovascular research (Fig. 2). We have reviewed the basic requirements and scope for major funding mechanisms including grants from the NIH, medical societies, specific institutional-level funding and industry. We have also outlined characteristics of applications for these grants, which may increase the likelihood of successfully acquiring funding. Despite the recent reduction in the availability and scale of historic funding mechanisms, the future of cardiovascular junior investigators remains bright as alternative grants and submission mechanisms are explored in addition to standard governmental and societal grants. 


\section{Acknowledgments}

Funding No extramural funding.

\section{References}

1. Sumandea CA, Balke CW. Funding opportunities for investigators in the early stages of career development. Circulation. 2009; 119:1320-1327. [PubMed: 19273733]

2. McDonagh KT. Identifying grant funding: mentored career development and transition awards. Hematol Am Soc Hematol Educ Program. 2008; 12:12-15.

3. Gill TM, McDermott MM, Ibrahim SA, Petersen LA, Doebbeling BN. Getting funded. Career development awards for aspiring clinical investigators. J Gen Intern Med. 2004; 19:472-478. [PubMed: 15109347] 


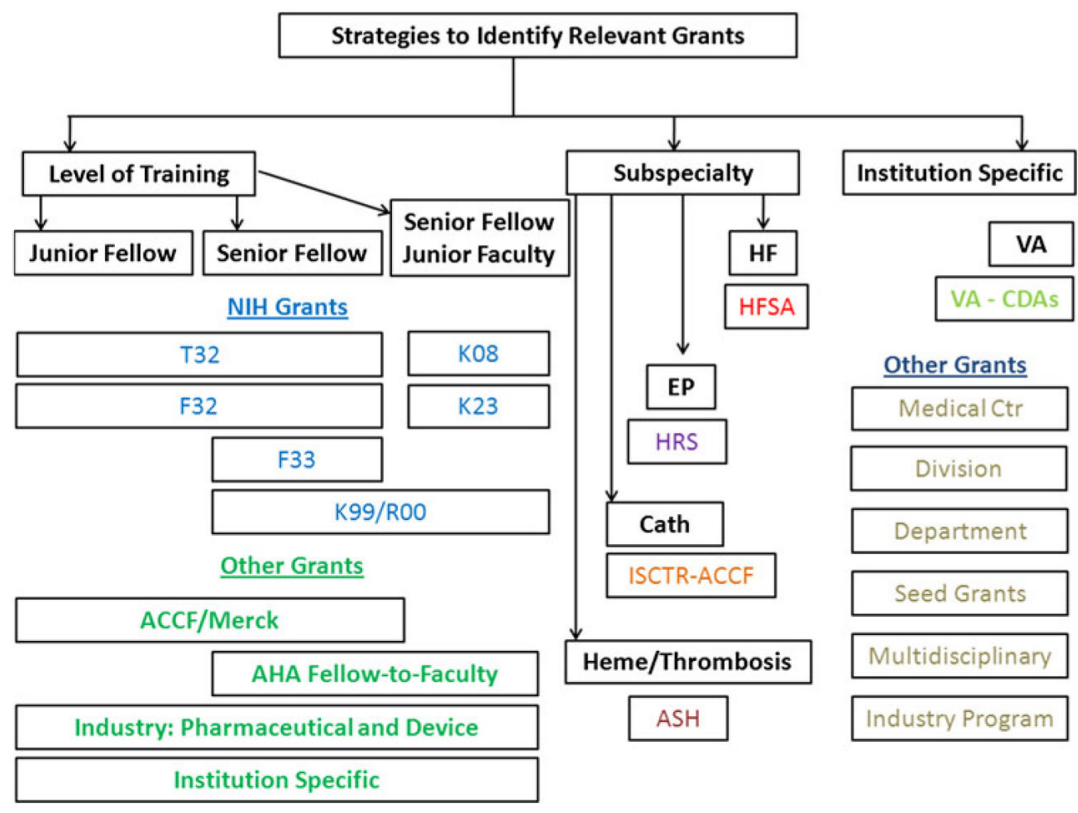

Fig. 1.

Potential algorithm for early career investigators to identify grants and funding opportunities. ACCF American College of Cardiology Fellowship, AHA American Heart Association, HF Heart Failure, HFSA Heart Failure Society of America, EP Electrophysiology, HRS Heart Rhythm Society, ISCTR International Society for Cardiovascular Translational Research, ASH American Society of Hematology, VA Veterans Affairs, CDAs Career Development Awards, Ctr Center 


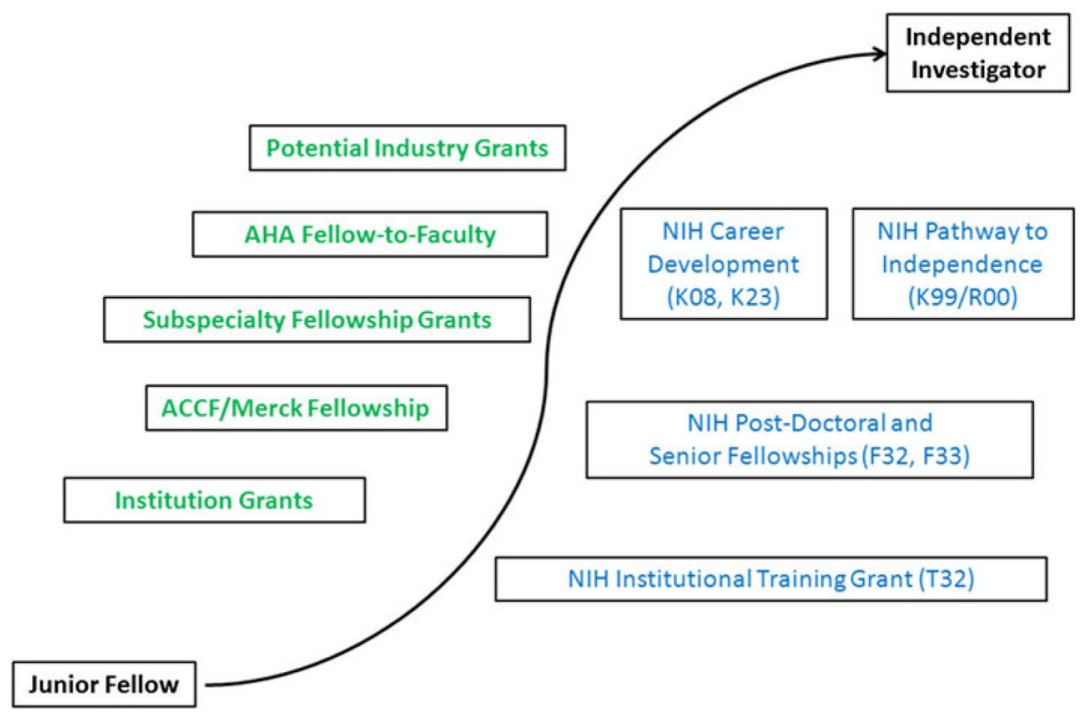

Fig. 2.

Potential training and career development awards pathway for individuals with a health professions doctorate. ACC American College of Cardiology, AHA American Heart Association, NIH National Institutes of Health 
Table 1

Examples of sources of support for early career investigators

\begin{tabular}{ll}
\hline Funding source & Website \\
\hline $\begin{array}{l}\text { NIH Extramural Research } \\
\text { Training Programs }\end{array}$ & http://grants.nih.gov/training/extramural.htm \\
$\begin{array}{l}\text { Veterans Affairs Career } \\
\text { Development Awards }\end{array}$ & http://www.research.va.gov/programs/csrd/career_dev.cfm \\
American Heart Association & http://my.americanheart.org/professional/Research/FundingOpportunities/Funding-Opportunities_UCM_316909_SubHomePage.jsp \\
$\begin{array}{l}\text { American College of } \\
\text { Cardiology }\end{array}$ & http://www.cardiosource.org/ACC/About-ACC/Awards-Program/Research-and-Career-Development-Awards.aspx \\
$\begin{array}{l}\text { Heart Failure Society of } \\
\text { America }\end{array}$ & http://www.hfsafellowship.org \\
$\begin{array}{l}\text { Heart Rhythm Society } \\
\text { Fellowship }\end{array}$ & http://www.hrsonline.org/Career-Resources/Fellowships-Program-Directors/Scholarships-for-EP\#axzz2XumQbciO \\
American Society of & http://www.hematology.org/Awards/RTAF/2628.aspx \\
Hematology & \\
\hline
\end{tabular}


Table 2

NIH grant overview for early career investigators

\begin{tabular}{|c|c|c|c|}
\hline Mechanism & Program description & Details & Website \\
\hline F32 & $\begin{array}{l}\text { Ruth L. Kirschstein National } \\
\text { Research Service Awards } \\
\text { (NRSA) for Individual } \\
\text { Postdoctoral Fellows (Parent } \\
\text { F32) (PA-11-113) }\end{array}$ & $\begin{array}{l}\text { Mentor-supervised emersion } \\
\text { Trainees with little or no } \\
\text { research experience } \\
\text { Up to } 3 \text { years of aggregate } \\
\text { Kirschstein-NRSA support at the } \\
\text { postdoctoral level }\end{array}$ & http://grants1.nih.gov/grants/guide/pa-files/PA-11-113.html \\
\hline F33 & $\begin{array}{l}\text { Ruth L. Kirschstein National } \\
\text { Research Service Awards } \\
\text { (NRSA) for Individual } \\
\text { Senior Fellows (Parent F33) } \\
\text { (PA-11-114) }\end{array}$ & $\begin{array}{l}\text { Senior fellows } \\
\text { Individuals with at least } 7 \text { years } \\
\text { of research experience beyond } \\
\text { the doctorate } \\
\text { Usually sabbatical experience }\end{array}$ & http://grants1.nih.gov/grants/guide/pa-files/PA-11-114.html \\
\hline T32 & $\begin{array}{l}\text { Ruth L. Kirschstein National } \\
\text { Research Service Award } \\
\text { (NRSA) Institutional } \\
\text { Research Training Grants } \\
\text { (T32) (PA-11-184) (See } \\
\text { NOT-OD-11-060) }\end{array}$ & $\begin{array}{l}\text { Awarded to institutions that train } \\
\text { fellows and residents } \\
\text { Cumulative minimum of } 2 \text { years } \\
\text { Pursue research full time }\end{array}$ & http://grants.nih.gov/grants/guide/pa-files/PA-11-184.html \\
\hline K08 & $\begin{array}{l}\text { Mentored Clinical Scientist } \\
\text { Research Career } \\
\text { Development Award (Parent } \\
\text { K08) (PA-11-193) }\end{array}$ & $\begin{array}{l}\text { Clinician-scientists } \\
\text { Laboratory and cardiovascular } \\
\text { epidemiological and health } \\
\text { services research }\end{array}$ & http://grants1.nih.gov/grants/guide/pa-files/PA-11-193.html \\
\hline K23 & $\begin{array}{l}\text { Mentored Patient-Oriented } \\
\text { Research Career } \\
\text { Development Award (Parent } \\
\text { K23) (PA-11-194) }\end{array}$ & $\begin{array}{l}\text { Research-oriented clinicians } \\
\text { Patient-oriented research } \\
\text { conducted with human subjects }\end{array}$ & http://grants1.nih.gov/grants/guide/pa-files/PA-11-194.html \\
\hline K99/R00 & $\begin{array}{l}\text { NIH Pathway to } \\
\text { Independence Award (Parent } \\
\text { K99/R00) (PA-11-197) }\end{array}$ & $\begin{array}{l}1-2 \text { years of mentor-supervised } \\
\text { postdoctoral training } \\
3 \text { years of independent research } \\
\text { within the context of the first } \\
\text { junior faculty position } \\
75 \% \text { of total professional effort } \\
\text { to research }\end{array}$ & http://grants1.nih.gov/grants/guide/pa-files/PA-11-197.html \\
\hline
\end{tabular}

